\title{
El diputado conseguidor: representación política particularista en el Congreso de la República Dominicana (1998-2010)
}

The Congressman facilitator: Particularistic political representation in the Dominican Republic House of Representatives (1998-2010)

\author{
ANA B. BENITO \\ Centro de Estudios Políticos y Constitucionales, Madrid
}

\section{Cómo citar/Citation}

Benito, A. B. (2017). El diputado conseguidor: representación política particularista en el Congreso de la República Dominicana (1998-2010). Revista Española de Ciencia Política, 44, 151-179. Doi: https://doi.org/10.21308/recp.44.06

\section{Resumen}

Este trabajo propone una clasificación del nivel de inclusividad de las proposiciones de ley para conocer cuál ha sido papel del Poder Legislativo en el arraigo o declive de la responsividad particular en la República Dominicana en el periodo 1998-2010, identificando variables institucionales y partidistas que condicionan el peso de los asuntos del distrito en las labores de representación. Los datos estadísticos evidencian que la personalización y la selección estratégica han prevalecido sobre la generalidad y la abstracción del mandato, limitando la vocación universal de la política pública del Poder Legislativo.

Palabras clave: particularismo legislativo, clientelismo, representación política, República Dominicana.

\begin{abstract}
This work proposes a classification of the degree of inclusiveness of law proposals to explore the role of the Dominican Legislative Power in the establishment or decline of particularistic responsiveness during the period from 1998 to 2010. It does so by identifying the institutional and party variables which influence the weight of district matters in the exercise of political representation. Statistical data shows that individualization and strategic selection prevail over the generality and abstraction of the mandate of representation, thus limiting the universal orientation of the public policy by the Legislative power.

Keywords: legislative particularism, clientelism, political representation, Dominican Republic.
\end{abstract}




\section{INTRODUCCIÓN}

En 1996 comenzó en la República Dominicana la etapa de la consolidación democrática tras tres décadas de política caudillista de los líderes Joaquín Balaguer (PRSC), Juan Bosch (PLD) y Francisco Peña Gómez (PRD) ${ }^{1}$. Desde entonces, el país ha experimentado un proceso de modernización económica y reforma del Estado que debería haber impulsado la redistribución y modelado el tipo de representación política en democracia. En el periodo 2004-2010, la economía dominicana creció por encima de la media de sus vecinos latinoamericanos (4,7\% PIB), siendo hoy un país de renta media alta que ha dejado de ser prioridad para los organismos internacionales de ayuda oficial al desarrollo. Esta pujanza económica y el arraigo de la democracia electoralista deberían haber confirmado los augurios de las teorías económicas de la democracia y sus efectos redistributivos (Kuznets, 1955; Meltzer y Richard, 1981) y de aquellas que profetizaban que la modernización del Estado acabaría con las relaciones particularistas en la representación política (Landé, 1977; Eisenstadt y Lemarchand, 1981). Sin embargo, a pesar del reordenamiento de fuerzas y electores, persiste la vocación particularista en la movilización y representación. En 2010, República Dominicana ocupaba el primer lugar en la escala de clientelismo según el Barómetro de Las Américas (LAPOP, 2010), en reparto de prebendas en campaña electoral por parte de los legisladores (PELA, 2010), y se situaba en la comparación mundial entre los tres países más clientelares junto a Senegal y Mongolia (Kitschelt y Kselman, 2011: 33), siendo además uno de los países con menor porcentaje de gasto social y de elevada desigualdad ${ }^{2}$.

La política particularista es un modo de accountability que opera como mecanismo de vinculación racional entre principal-agente a través de un intercambio directo, predecible y supervisado (Kistchelt y Wilkinson, 2012) y es una estrategia, tanto de los patronos para adquirir y mantener el poder, como de los clientes para promover sus intereses (Piattoni, 2001). En la competición particularista los políticos realizan una asignación selectiva de recursos para maximizar sus probabilidades de reelección (Seddon et al., 2002; Indridason, 2007). Servicio en la circunscripción, política de conseguidores (brokers), pork barrel, clientelismo, nuevo populismo fiscal, patronazgo o neopatrimonialismo entre otras, son las distintas formas en que se promocionan intereses particulares sin tener en cuenta o incluso a costa del interés general (Piatonni, 2001:3). La atención prestada al clientelismo como uno de los subtipos más comunes de particularismo ha derivado en la práctica de referirse al «todo» (política particularista) por la "parte» (clientelismo), aunque la literatura reconoce tal diferencia y se utilicen indistintamente. La responsividad particular y la de naturaleza universal son manifestaciones de la dimensión sustantiva de la representación -receptividad de los

1. Partido Reformista Social Cristiano (PRSC), Partido de la Liberación Dominicana (PLD) y Partido Revolucionario Dominicano (PRD).

2. Coeficiente de Gini: 47,8 en 1983 y 47,2 en 2010. 
políticos a los intereses de los ciudadanos (Pitkin, 1967)- y su elección dependerá de los incentivos que enfrenten para comportarse como rent seekers o policy seekers.

La mayoría de los trabajos sobre la selección estratégica de beneficiarios en las decisiones públicas se han centrado en el análisis de los programas del Ejecutivo (Nitcher, 2008; Ansolabehere y Snyder, 2003; De la Calle, 2005; Stokes, 2005; Rosas y Hawkins, 2008), siendo escasa la atención prestada al Legislativo como agente con poder para distribuir (asignación recíproca del coste/beneficio) y redistribuir (costes repartidos entre categorías abstractas de votantes). Con este propósito, el artículo explora cuál ha sido papel del Poder Legislativo en el arraigo y/o declive de la responsividad particular en la República Dominicana en la etapa de la consolidación democrática. A pesar de ser numerosos los trabajos sobre la actividad legislativa en los presidencialismos latinoamericanos y su efecto en las relaciones de gobernabilidad (Cox et al., 2001; Siavelis y Morgenstern, 2008; Amorim y Santos, 2003; Mejía et al., 2009; García Montero, 2008, entre otros), ninguno de ellos ha incluido a la República Dominicana entre sus casos de estudio.

Para medir el grado de particularismo en la representación legislativa el artículo se organiza en tres apartados. Primeramente se propone una clasificación del grado de inclusividad de las proposiciones de ley. En segundo lugar, se examinan los cambios y continuidades en la vocación particularista de la actividad propositiva de los diputados dominicanos desde 1998 hasta 2010, identificando las variables institucionales y partidistas que condicionan el peso de los asuntos del distrito en las labores de representación nacional. En el apartado de conclusiones se presentan los hallazgos más importantes y se reflexiona sobre el carácter marginal y distributivo del Legislativo dominicano frente al Ejecutivo en el marco de un sistema de partidos no programáticos.

\section{¿CÓMO MEDIR EL PARTICULARISMO EN EL LEGISLATIVO?}

El acercamiento a la producción legislativa como variable dependiente ha generado diferentes clasificaciones del tipo de leyes promulgadas en las democracias contemporáneas. Tal es el caso del índice de Taylor-Robinson y Díaz (1999), construido según el nivel de agregación de intereses (individuales, locales, sectoriales, regionales y nacionales) y su efecto (beneficiosas, contraproducentes, mixtas y neutras); el elaborado por Amorim y Santos (2003), que introducía el tópico de las leyes (administrativas, económicas, honorificas, presupuestarias, políticas y sociales) junto a las variables anteriores de agregación y efecto; o el propuesto por Mejía et al.(2009), que retoma las categorías de Lowi (1964) (distributivas, redistributivas y regulatorias) para determinar el carácter particularista o general de una ley. Todas estas mediciones consideran la suerte final del proyecto en el trámite parlamentario. Sin embargo, Congreso y Senado son escenarios complejos de ambición individual, grupos de interés y ciclos de mayorías que obstaculizan la cooperación y pueden llegar a distorsionar el interés público (Shepsle y Boncket, 1997). En este proceso, el mandato entre principal-agente sigue un iter institucional (agenda setting, ciclos de mayorías, conquista de apoyos...) que puede afectar a su contenido y desenlace y, por lo tanto, no reflejaría la 
naturaleza de la representación del universo de mandatos que el legislador recibe en su circunscripción y que deberá hacer cumplir en las instituciones.

Para contrarrestar este sesgo de las mediciones que tienen en cuenta el éxito legislativo (leyes promulgadas), este trabajo propone caracterizar el grado de inclusividad de la representación centrándose en la etapa propositiva, analizando la actividad de los diputados en ausencia de tales filtros institucionales y, por lo tanto, más cercana en el tiempo al acto de delegación entre principal-agente. Las proposiciones de ley aportan información relevante de las funciones normativas y de orientación de la política pública del Poder Legislativo en las que identificar la vocación particularista o universal de la representación.

Con la tipificación que resulte de los distintos niveles de agregación de destinatarios representados (ciudadanía, colectivo concreto o un particular) y del interés protegido (público, grupal/de club o personal) de las iniciativas legislativas, hablaremos de «representación general» ante aquellas proposiciones cuyas resultas generarán derechos y deberes para la ciudadanía sin posibilidad de restricción a un determinado grupo o individuo. Un acto de delegación en el que el agente representa los intereses públicos del principal-ciudadano y no tienen cabida los mandatos particulares imperativos. En la categoría de "representación corporativa» se clasifican las proposiciones cuyos beneficios y/o cargas se dirigen a un grupo delimitado que comparte un mismo interés, mientras que la «representación individual» acoge aquellas cuyos beneficios solo pueden ser disfrutados y/o soportados por una sola persona.

TABLA 1.

TIPO DE REPRESENTACIÓN

\begin{tabular}{lccc}
\hline & General & Corporativa & Individual \\
\hline Principal representado & ciudadanía & colectivos & particulares \\
\hline Interés protegido & interés público & interés grupal/ de club & interés personal \\
\hline
\end{tabular}

Fuente: elaboración propia.

Para corroborar la validez de esta tipología que se propone a partir del caso dominicano, se precisan nuevos estudios de caso y en perspectiva comparada que aporten evidencia acerca del vínculo entre principal-agente y su relación con el mayor o menor peso de la asignación selectiva o universal de bienes públicos en el escenario legislativo. Esto permitirá formular un modelo que explique cómo y por qué asumen los costes e incentivos los legisladores de otras democracias de competencia clientelar.

\section{Principal representado e intereses protegidos en la República Dominicana, 1998-2010}

En las tres legislaturas estudiadas se aprobaron en la Cámara de Diputados un total de 1863 proposiciones de ley para su trámite parlamentario y fueron clasificadas 
siguiendo la tipología propuesta ${ }^{3}$. Además de la ciudadanía dominicana receptora de los derechos y deberes de las proposiciones de vocación universal, los grupos destinatarios en las iniciativas de naturaleza corporativa resultaron ser tres: empresarios, diversos colectivos de trabajadores o gremios y autoridades locales. En los primeros, la finalidad era conceder algún tipo de exención o regulación favorable; en los segundos beneficios de club a sus asociados, y en los terceros la elevación de categoría territorial a una unidad poblacional ubicada en la provincia del diputado. Con respecto a las que promueven intereses empresariales, todas las presentadas en el periodo 1998-2010 tenían por finalidad la exoneración o régimen especial para determinados sectores de la industria y el comercio nacional. Esta intervención del Estado en la regulación económica por la vía de exenciones, reglas favorables y subvenciones, es el contexto de capitalismo coordinado identificado por Kitschelt y Wilkinson (2012) como propicio para las relaciones de intercambio particularizado con los «clientes ricos pero pobres en votos», y una de las posibles estrategias de las élites para moldear a su favor la legislación fiscal e impositiva (Quinn y Shapiro, 1991; Fairfeld, 2010; Gilens, 2012; Boucoyannis, 2015). En cuanto a los grupos a los que se propone asignar bienes de club, los colectivos elegidos eran profesionales liberales, como las organizaciones locales de periodistas, abogados o funcionarios de ciertas agencias públicas. Como muestran los ejemplos seleccionados en la tabla 2, el diputado ejerce de mediador ante el Estado proponiendo un aumento salarial para los funcionarios de su provincia; la concesión de una pensión para 37 trabajadores de una empresa pública, o una nueva conquista en el sistema especial de jubilación para el colectivo de transportistas, uno de los grupos de interés más influyentes del país ${ }^{4}$.

Con respecto a las que el diputado propone elevar la categoría territorial ${ }^{5}$ de una unidad administrativa dentro de su circunscripción, es importante señalar que el estatus municipal asegura una transferencia mínima mensual, por lo que este instrumento ha incentivado en los últimos años la creación de unidades administrativas a un ritmo acelerado. En $48442 \mathrm{~km}^{2}$ y 10 millones de habitantes se concentraban en 2010 un total de 387 municipalidades. El sistema de pisos mínimos en la asignación de recursos fue calificado por el Banco Interamericano de Desarrollo (BID) como un «incentivo perverso hacia la creación artificial de distritos municipales, fragmentando municipios y creando inadecuadas economías de escala para la prestación de servicios públicos locales» (Ramírez, 2010: 7). Puesto que el cambio de categoría se gestiona en

3. Datos proporcionados por la Oficina Acceso a la Información (OAI) de la Cámara de Diputados. En adelante OAI-CD/RD. Iniciativas registradas en el orden del día y tomadas en consideración (art. 74 del Reglamento Cámara de Diputados, 2010).

4. Agrupa a pequeños empresarios que controlan el transporte urbano. Conocidos popularmente como «los dueños del país», son beneficiarios de la transferencia pública de mayor cuantía («Bono Gas Choferes»).

5. Jerarquía de las entidades municipales en orden ascendente: paraje, sección, distrito municipal y municipio (art. 22 y ss. Ley 176 de 2007). 
TABLA 2.

Ejemplos de proposiciones de ley en la República Dominicana (1998-2010)

\begin{tabular}{|c|c|c|c|}
\hline Representación & Beneficiarios & & Proyecto \\
\hline \multirow{5}{*}{ General } & \multirow{5}{*}{ Ciudadanía } & pl00638 & Crear el Código del Agua \\
\hline & & pl02757 & $\begin{array}{l}\text { Crear la asignatura de educación vial en los planteles } \\
\text { escolares }\end{array}$ \\
\hline & & pl04339 & $\begin{array}{l}\text { Autorizar canje de bonos soberanos por nuevos ins- } \\
\text { trumentos financieros para hacerlos compatibles } \\
\text { con la capacidad de repago de las finanzas públicas }\end{array}$ \\
\hline & & pl01811 & Declarar el día del niño por nacer \\
\hline & & pl03957 & $\begin{array}{l}\text { Designar «Autopista Joaquín Balaguer» la carretera } \\
\text { Santiago-Navarrete }\end{array}$ \\
\hline \multirow{7}{*}{ Corporativa } & \multirow{2}{*}{ Empresarios } & pl01289 & $\begin{array}{l}\text { Modificar Ley } 14-93 \text { para establecer tasa cero a la } \\
\text { importación de sardinas y bacalao }\end{array}$ \\
\hline & & pl01748 & $\begin{array}{l}\text { Modificar Ley } 168 \text { para facilitar la exoneración de } \\
\text { impuestos a vehículos importados }\end{array}$ \\
\hline & \multirow{3}{*}{$\begin{array}{l}\text { Gremios } \\
\text { trabajadores }\end{array}$} & pl03784 & $\begin{array}{l}\text { Modificar ley } 547 \text { que crea la caja de jubilaciones } \\
\text { para transportistas }\end{array}$ \\
\hline & & pl00747 & $\begin{array}{l}\text { Conceder un aumento de salario a los servidores } \\
\text { públicos, civiles y militares que desempeñen funcio- } \\
\text { nes en la provincia fronteriza }\end{array}$ \\
\hline & & pl03956 & $\begin{array}{l}\text { Conceder pensión mensual a } 37 \text { ex-empleados del } \\
\text { Instituto Nacional del Algodón }\end{array}$ \\
\hline & \multirow{2}{*}{$\begin{array}{l}\text { Autoridades } \\
\text { locales }\end{array}$} & pl00366 & $\begin{array}{l}\text { Elevar a distrito municipal la sección Maizal, muni- } \\
\text { cipio Esperanza, provincia Valverde }\end{array}$ \\
\hline & & pl01388 & $\begin{array}{l}\text { Elevar el paraje El Ranchito a sección, provincia La } \\
\text { Vega }\end{array}$ \\
\hline \multirow{3}{*}{ Individual } & \multirow{3}{*}{ Particulares } & pl08686 & $\begin{array}{l}\text { Conceder pensión mensual del Estado de } \$ 45,000 \\
(1,000 \text { USD) a Franc. G. y Adolfo F. }\end{array}$ \\
\hline & & pl01833 & $\begin{array}{l}\text { Conceder una pensión mensual del Estado de } \\
\$ 2,000 \text { (50 USD) a Ana P. }\end{array}$ \\
\hline & & ploc & $\begin{array}{l}\text { Aumentar pensión mensual del Estado de Ramón } \\
\text { U. y Ramón G. a \$8,000 (180 USD). }\end{array}$ \\
\hline
\end{tabular}

Fuente: elaboración propia con datos de OAI-CD/RD.

el Congreso, la promesa de elevación territorial se ha convertido en el premio que otorga el diputado a las autoridades locales de su provincia por la movilización proselitista. El uso del territorio como prebenda es una manifestación más del clientelismo entre élites en el que se intercambian influencia y apoyo político.

En la categoría «representación individual» todas las propuestas que beneficiaban a una sola persona tenían por finalidad conceder una pensión a un ciudadano. La 
seguridad social dominicana se creó en 2001 bajo un régimen mixto de capitalización individual y reparto a cargo del Estado para sus empleados. En 2010 protegía al 45\% de la población, aunque no todos los componentes tienen actualmente el mismo grado de cobertura y ejecución. El de maternidad comenzó en 2008 y el de salud cubría en el año 2010 solo al $24 \%$ de la población (IDSS, 2015). El gran reto de la protección social dominicana es su universalización y la implementación del régimen subsidiado para los trabajadores informales, que representan el $56,5 \%$ de la población activa nacional.La potestad de las autoridades de incluir beneficiarios especiales al margen de los protocolos reglamentarios acentúa el carácter particularista del sistema de pensiones en el país. Este acceso privilegiado resultado de la liberalidad del conseguidor y no de un derecho adquirido las hace susceptibles de ser utilizadas con fines movilizadores por el universo de patronos que ejercen de mediadores: presidente y gobernador, senador y diputado, y en el escenario local el alcalde y los concejales. La tabla 2 muestra la discrecionalidad de la cuantía en las pensiones propuestas, que oscilan entre los mil y los cincuenta dólares mensuales, sin que su actualización estuviera sujeta a criterios generalistas relativos a la inflación o categoría profesional.

Se sostiene como hipótesis que el mandato de representación en la República Dominicana tiene un marcado focus distrital influenciado por variables institucionales como el sistema electoral (financiamiento, magnitud del distrito, voto preferencial); el diseño territorial (fragmentación dependiente), y las relaciones Legislativo-Ejecutivo (distribución de tareas, papel marginal). Desde el sistema de partidos, el vínculo no programático de la competición partidista y el perfil de la clase política (élites extractivas, cooptación de políticas) favorecen la defensa de intereses localistas en el hemiciclo dominicano. El escenario de oportunidad de mayorías y minorías no es tan determinante para la representación de intereses generalistas, como los juegos de veto para hacerse con el monopolio de la actividad concesional particularista.

\section{CAMBIOS Y CONTINUIDADES EN LA VOCACIÓN PARTICULARISTA DE LA ACTIVIDAD PROPOSITIVA (1998-2010)}

\section{Servidores del distrito: representación "desde abajo»}

Entre 1998 y 2010, menos de la mitad de las proposiciones de ley promovían el interés general $(49,7 \%)$, siendo muy escasa la actividad fiscalizadora del Legislativo dominicano sobre la acción del Gobierno, que ha oscilado entre el 0,41 \% y 1,22\% de la actividad propositiva. Por el contrario, aquellas que gestionaban la concesión de una pensión a un elector de su circunscripción alcanzaron el 34,6\% del total.

La actividad propositiva corporativa ha representado en la década estudiada el 15,6\% del total agregado. Las propuestas de exenciones a diferentes sectores y grupos de interés, anuncian el escenario del «capitalismo coordinado» (Kitschelt y Wilkinson, 2012), caracterizado por el predominio de empresas públicas subsidiadas y/o privadas con regímenes diferenciados que moviliza a los empresarios en busca de vínculos clientelares. Solo entre 
TABLA 3.

ACTIVIDAD PROPOSITIVA SEGÚN NIVEL DE PARTICULARISMO (1998-2010)

\begin{tabular}{|c|c|c|c|c|c|c|c|c|c|c|c|}
\hline \multirow[b]{2}{*}{ Legislatura } & \multicolumn{5}{|c|}{ General } & \multicolumn{4}{|c|}{ Corporativa } & \multicolumn{2}{|c|}{ Individual } \\
\hline & \multicolumn{4}{|c|}{$\begin{array}{l}\text { Ciudadanos } \\
\text { dominicanos }\end{array}$} & $t$ & Autoridades & Empresarios & Gremios & $t$ & Particulares & $t$ \\
\hline \multirow{2}{*}{ 1998-02 } & & (g1) & (g2) & (g3) & & 98 & 20 & 11 & 129 & 185 & 185 \\
\hline & $\begin{array}{l}\mathbf{N} \\
\%\end{array}$ & $\begin{array}{c}355 \\
49,58\end{array}$ & $\begin{array}{c}44 \\
6,14\end{array}$ & $\begin{array}{c}3 \\
0,41\end{array}$ & $\begin{array}{c}402 \\
56,14\end{array}$ & 13,68 & 2,79 & 1,53 & 18,01 & 25,83 & 25,83 \\
\hline \multirow{2}{*}{ 2002-06 } & $\mathbf{N}$ & 168 & 48 & 9 & 225 & 99 & 11 & 3 & 113 & 398 & 398 \\
\hline & $\%$ & 22,82 & 6,52 & 1,22 & 30,57 & 13,45 & 1,49 & 0,40 & 15,35 & 54,07 & 54,07 \\
\hline \multirow{2}{*}{ 2006-10 } & $\mathbf{N}$ & 182 & 71 & 4 & 257 & 42 & 8 & 7 & 57 & 97 & 97 \\
\hline & $\%$ & 44,28 & 17,27 & 0,97 & 62,53 & 10,21 & 1,94 & 1,70 & 13,86 & 23,95 & 23,95 \\
\hline$T$ & \multicolumn{5}{|c|}{$(\mathrm{N}=885) 49,7 \%$} & \multicolumn{4}{|c|}{$(\mathrm{N}=298) \mathbf{1 5 , 6 \%}$} & \multicolumn{2}{|c|}{$(\mathrm{N}=680) 34,6 \%$} \\
\hline
\end{tabular}

(g1): finalidad desarrollo legislativo/instituciones; (g2) finalidad testimonial; (g3) finalidad fiscalizadora.

Fuente: elaboración propia con datos de OAI-CD/RD.

2008 y 2010 se promulgaron siete leyes de exoneraciones fiscales y el Gobierno dominicano dejó de recibir el equivalente al $5 \%$ del PIB por este concepto (CREES, 2013). La penetración de los intereses particulares en la actividad legislativa de naturaleza corporativa podría estar influenciada por la financiación de los partidos y el perfil de la clase política nacional. Además de la asignación pública regular, la ley electoral permite donaciones privadas para las que no establece límite ni obligatoriedad de identificar al donante. Esta laxitud en la regulación hace permeables las instituciones a los intereses corporativos de aquellos que financian las campañas y a los que habría que devolver el favor a través de una legislación favorable ${ }^{6}$. El coste de las campañas hace insuficiente la aportación del Estado, incrementándose así la dependencia del financiamiento privado así como la presencia de la figura del empresario-político con recursos: «Ahora presentamos en el municipio una boleta de banqueros, colmaderos y comerciantes [...] porque los dirigentes políticos, los que están preparados para dirigir el Estado, no tienen capacidad económica. Tienen el liderazgo, pero viene un «Juan» con dinero y conquista, porque el elector está esperando que le den 100 pesos» (Benito y Rosales, 2011: 29).

La compatibilidad de las funciones de representación con actividades empresariales genera un escenario en el que pueden surgir conflictos de interés entre el fin primario institucional y el eventual corporativo, comprometiendo la integridad y la generalidad del mandato (Krehbiel, 2004; Acemoglu y Robinson, 2006). La falta de exclusividad en las labores parlamentarias dibuja un perfil del legislador dominicano

6. Las ramificaciones del caso Odebrecht en República Dominicana han llevado a decretar prisión preventiva para miembros del comité político del partido oficialista, asesores de campaña y dos expresidentes de la Cámara de Diputados por aceptar sobornos para lograr la asignación de obras a favor de la empresa brasileña. Ver noticia del periódico Diario Libre del 3 de junio de 2017. 
en el que predominan los patronos privados con funciones públicas ${ }^{7}$. Sirva como ejemplo alguno de los curriculum vitae que los propios legisladores cuelgan en la web de la Cámara a modo de rendición de cuentas, donde se puede apreciar los rasgos corporativistas de la representación en el país. El diputado y presidente de la Federación Nacional de Comerciantes Detallistas de Provisiones, Pablo Adón, se presentaba ante sus ciudadanos con las siguientes palabras:

El legislador y dirigente comercial ha encabezado la representación de su sector en foros nacionales e internacionales. A parte de su defensa del sector detallista, ha dejado testimonio de su trabajo en boletines, periódicos y programas de televisión. Es autor del libro El Detallista del 2001 como herramienta para desarrollar estrategias que permita al colmado dominicano subsistir en la globalización.

Este tipo de dinámicas ilustran el portafolio de estrategias de las élites económicas para capturar el compromiso de la clase política -tal como identificaran Bogliaccini y Luna (2016) en Chile y Uruguay-, que dificultan la aprobación de reformas redistributivas.

Con respecto a las propuestas de elevación de categoría territorial, la mayoría fueron gestionadas en las dos primeras legislaturas en las que el PRD controlaba los escaños parlamentarios y el Ejecutivo (98 solicitudes en 1998-2002 y 99 en 2002-2006), aunque como muestra el gráfico 1 es en el año 2007 cuando este tipo de actividad propositiva alcanzó su pico máximo $(44 \%)$ en el cómputo anual. En este periodo tiene lugar el grueso de la microfragmentación del territorio dominicano ${ }^{8}$. En 2011, y tras la alarma por el incremento de las demarcaciones territoriales, Congreso y Senado llegaron a un acuerdo para dejar morir estos proyectos en trámite parlamentario a la espera de que se apruebe la ley de ordenamiento territorial. En ausencia de carrera civil, la inyección presupuestaria para financiar el aparato personal y logístico del nivel administrativo otorgado ha alimentado el intercambio de votos por empleos en las nuevas demarcaciones locales con un patrón similar al patronazgo que impera en la Administración central (Suárez, 2013: 24) ${ }^{9}$. Las siguientes opiniones ilustran la instrumentalización de la fragmentación territorial y de la relación entre el diputado y las autoridades locales:

7. En la legislatura 2010-2016 ejercían como diputados los presidentes de la Asociación Nacional Productores Agrícolas, del Colegio Dominicano de Ingenieros y Arquitectos, de los Propietarios de Supermercados Provincia Duarte, del Consorcio Arrocero El Pozo, la Asociación Nacional Propietarios de Taxi, la Federación Nacional Comerciantes Detallistas de Provisiones, Federación Nacional de Transporte, la Asociación Ganaderos de la Provincia La Vega, o la Federación Nacional de Comerciantes, entre otros.

8. Entre 1995 y 2010 el total de municipios pasó de 108 a 155, y los distritos municipales de 44 a 232 .

9. Desde 2004 a 2010 solo 217 de los 479400 funcionarios accedieron por concurso $(0,04 \%$ del total y el $0,37 \%$ de los servidores de la carrera administrativa). 
En su mayoría, los proyectos [de elevación de categoría territorial] buscan controlar políticamente campitos y callejones que no cuentan con las características necesarias para cambiar de nivel. Y en la práctica, demuestra que los distritos municipales y municipios terminan como cacicazgos o aldeas controladas por los legisladores (De la Cruz, 2011: 2).

[...] Yo [alcalde] he hecho mucho por mi diputada. La gente que le hizo la campaña, están todas colocadas en mi Ayuntamiento» (Benito, 2015a: 117).

La legislatura 2002-2006 destaca por la vocación individualista del ejercicio de la representación, ya que las iniciativas que persiguen la concesión de una pensión al margen del sistema general de previsión alcanzaron el $54 \%$ del total. El gráfico 1 muestra su evolución ascendente, representando al inicio de la etapa de la consolidación democrática apenas el $2 \%$ del total en el año 1998 y llegando al $67 \%$ en el año 2006. La legislatura 2006-2010 marca un cambio de tendencia hacia la mayor vocación universal de la actividad propositiva del Congreso dominicano.

\section{Gráfico 1.}

ACTIVIDAD PROPOSITIVA ANUAL SEGÚN NIVEL DE PARTICULARISMO (\%) (1998-2010)

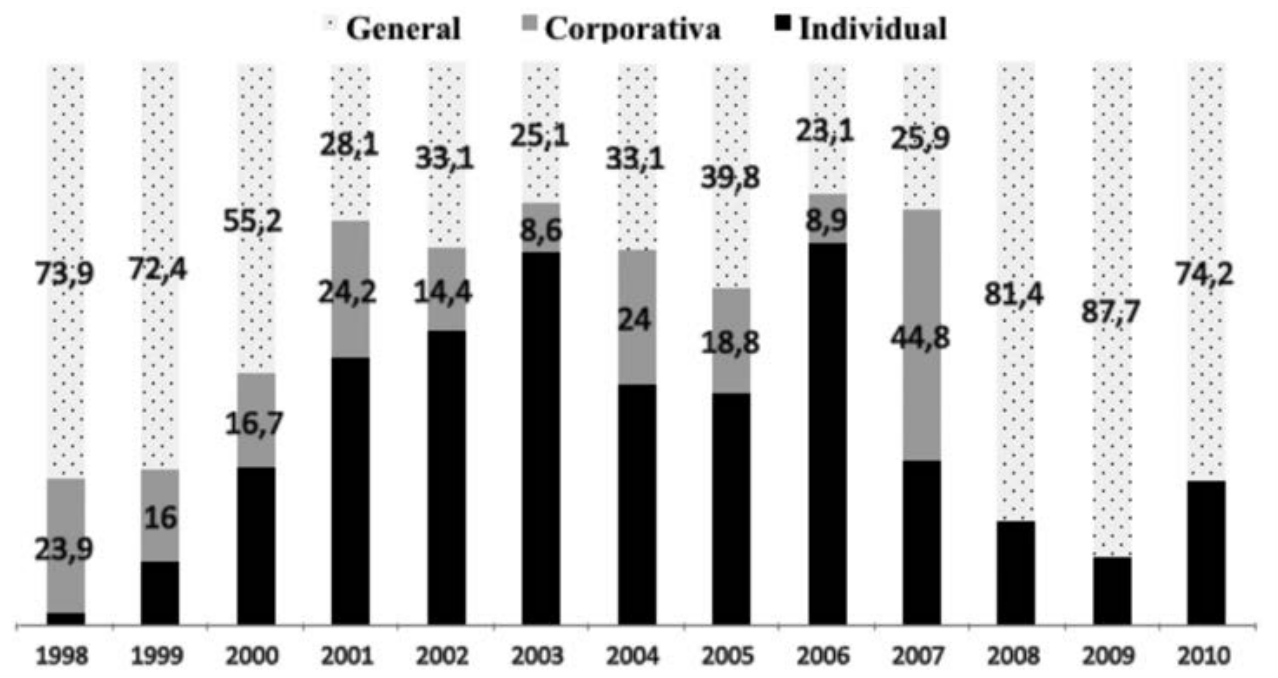

Fuente: elaboración propia con datos de OAI-CD/RD.

La evidencia muestra, por tanto, el predominio de la interacción de los «servidores del distrito» y «empresarios políticos» (Siavelis y Morgenstern, 2009: 105), en la que el diputado ejerce de conseguidor de derechos selectivos a través de una legislación particularista que atrae recursos públicos a sus distritos y atiende a los electores. Este condicionamiento de los intereses y presiones del distrito en su labor parlamentaria -»representación desde abajo» en la tipología de Andeweg y Thomassen (2005)- se asemeja al observado por Barreda y Ruiz (2015) en los diputados chilenos, frente al 
estilo de «representación desde arriba» de legisladores peruanos o bolivianos, más condicionados por los intereses del partido y su élite (Barreda y Ruiz, 2015: 27).

Esta independencia en el estilo de la representación se ve refrendada por las opiniones de los diputados dominicanos del Proyecto Elites Parlamentarias Latinoamericanas (PELA) de la Universidad de Salamanca cuando se les pregunta acerca de la fórmula para ganar elecciones y ser reelegido. «Tener presencia permanente» $(34 \%)$ y «hacerse con una reputación local» (31\%) parecen ser las claves para conquistar a los electores, lejos de fórmulas más generales de agregación de intereses como la de tener un programa o de organización partidista como contar con el apoyo de los líderes del partido. Ambas son indicadores de una vinculación personalista entre principal-agente donde prima el contacto regular y de un anclaje no programático basado en virtudes de lustre social. Para conseguir la reelección, además de la "presencia permanente» (33\%) el diputado debe, en opinión de los legisladores entrevistados, «atender a los electores del distrito" (36\%) (PELA, 2010). A partir de 2002, cuando la actividad propositiva particularista individual alcanza sus cotas máximas, la tasa de reelección aumenta 33 puntos porcentuales con respecto a la legislatura anterior y se mantiene en 2010 con la consolidación del dominio oficialista ${ }^{10}$. La nula relevancia del líder del partido en la conquista del escaño refleja la autonomía con la que opera la maquinaria electoral del candidato a diputado en la campaña, cuyo financiamiento se nutre fundamentalmente de recursos propios (Benito,2015a: 122).

TABLA 4.

RECOMENDACIONES PARA EL ÉXITO ELECTORAL (\%), 2010

\begin{tabular}{lcc}
\hline & Ganar & Ser reelegido \\
\hline Tener un programa & 11,35 & 2,8 \\
\hline Tener presencia permanente & $\mathbf{3 4 , 5 0}$ & $\mathbf{3 3 , 2}$ \\
\hline Regalar cosas & 1,4 & 2,9 \\
\hline Hacerse una reputación local & $\mathbf{3 1 , 3 5}$ & 20,2 \\
\hline Salir en la TV & 4,4 & 2,9 \\
\hline Atender a los electores de su distrito & 15,8 & $\mathbf{3 6 , 5}$ \\
\hline Tener el apoyo de los líderes del partido & 0 & 0 \\
\hline $\mathrm{T}$ & 100 & 100 \\
\hline
\end{tabular}

Fuente: Elaboración propia a partir de datos de PELA (2010), Universidad de Salamanca

El peso de los asuntos parroquiales y localistas del distrito en la actividad de los diputados apunta a una división del trabajo legislativo que se confirma al desagregar el contenido y finalidad de las propuestas que el Poder Ejecutivo sometió a trámite a la

10. Tasa de reelección Cámara de Diputados: 1998-2002 (13,4\%); 2002-2006 (46,6\%); 2006 $2010(46,6 \%)$. 
Cámara de Diputados. En las tres legislaturas observadas, el Ejecutivo presentó 35 iniciativas de naturaleza generalista, todas ellas major bills (Amorim y Santos, 2003) o futuras «leyes de agenda» (Zelaznik, 2012), además de las leyes generales de presupuesto.

TABLA 5.

Actividad Propositiva del Poder EjeCutivo, 1998-2010

\begin{tabular}{|c|c|c|c|c|c|c|c|}
\hline & \multicolumn{5}{|c|}{ Leyes de Agenda } & \multirow{2}{*}{$\begin{array}{c}\begin{array}{c}\text { Leyes de } \\
\text { Impor- } \\
\text { tancia }\end{array} \\
\\
4 \\
(10,8 \%)\end{array}$} & \multirow{2}{*}{$\begin{array}{c}\begin{array}{c}\text { Leyes no } \\
\text { Impor- } \\
\text { tantes }\end{array} \\
\\
-\end{array}$} \\
\hline General & $\begin{array}{c}7 \\
(18,9 \%) \\
\text { presupuestarias }\end{array}$ & $\begin{array}{c}9 \\
(24,3 \%) \\
\text { impositivas }\end{array}$ & $\begin{array}{c}12 \\
(32,4 \%) \\
\text { económicas }\end{array}$ & $\begin{array}{c}2 \\
(5,4 \%) \\
\text { empresas } \\
\text { públicas }\end{array}$ & $\begin{array}{c}1 \\
(2,7 \%) \\
\text { previsionales }\end{array}$ & & \\
\hline Corporativa & - & - & - & - & - & - & $2(5,4 \%)$ \\
\hline Individual & - & - & - & - & - & - & - \\
\hline $\mathbf{T}$ & & & & $(100 \%)$ & & & \\
\hline
\end{tabular}

Fuente: elaboración propia siguiendo las categorías de Zelanik (2012) con datos de OAI-CD/RD.

Escenarios de oportunidad normativa: partido en el gobierno y partido en la oposición

¿Cuál es el partido que ha liderado la función de orientación de la política pública en el Congreso en la etapa de la consolidación democrática? Cabría esperar una mayor vocación normativa en los diputados oficialistas que convierten en ley las propuestas del Gobierno de turno ("hacedores de leyes»), mientras que los diputados de la oposición ejercerían con mayor intensidad el papel de "conseguidores de beneficios» (vocación concesional) para sus votantes (García Montero, 2008; 2009). Por tanto, las proposiciones de ley generalistas contarían con un escenario propicio en aquellas legislaturas en las que los representantes oficialistas controlan tanto la mayoría de los escaños en la Cámara como el poder Ejecutivo, en una interacción propia del modelo de gobierno responsable (Hagopian, 2005). Las proposiciones de ley de vocación universal elevadas por diputados de la bancada mayoritaria tendrían menores oportunidades en un Ejecutivo controlado por el partido opositor (Gobierno dividido) (Mainwaring y Scott, 2002; Lanzaro, 2003; Chasquetti, 2008). Y el escenario más adverso sería aquel en el que un diputado opositor de un partido minoritario presenta iniciativas para implementar políticas públicas, ya que a la dificultad de sumar apoyos se une la resistencia oficialista a compartir la definición de políticas que desdibujen las fronteras entre gobierno-oposición y limiten el rédito electoral (Ellis et al., 2009).

En el periodo 1998-2002, en un hemiciclo de mayoría perredeísta (PRD) y Gobierno peledeísta (Leonel Fernández, PLD) los diputados oficialistas del PLD son los que presentan mayor número de iniciativas que promueven el interés general 
(80\%), a pesar de controlar solo el $30 \%$ de la Cámara, frente al $50 \%$ que elevan los representantes perredeístas, que controlan el $51 \%$ de los escaños. En el lado opuesto, el minoritario Partido Reformista Social Cristiano (PRSC) es quien destaca por someter el mayor número de proposiciones de naturaleza individual ( $46 \%$ de las propuestas).

TABLA 6.

ACTIVIDAD PROPOSITIVA SEGÚN NIVEL DE PARTICULARISMO Y PARTIDO, LEGISLATURA 1998-2002

\begin{tabular}{lccccccccccc}
\hline & & PLD & PRD & PRSC & $\begin{array}{c}\text { PLD/ } \\
\text { PRD/ } \\
\text { PRSC }\end{array}$ & $\begin{array}{c}\text { PLD/ } \\
\text { PRD }\end{array}$ & $\begin{array}{c}\text { PRD/ } \\
\text { PRSC }\end{array}$ & PPC & FNP & Otras & T \\
\cline { 3 - 12 } General & $\mathbf{N}$ & 77 & 131 & 51 & 24 & 12 & 11 & 4 & 4 & 74 & $(388)$ \\
& $\%$ & $\mathbf{8 0 , 2}$ & $\mathbf{5 0 , 6}$ & 40,2 & $\mathbf{5 5 , 8}$ & 27,3 & 52,4 & 30,8 & 80,0 & 81,3 & 55,5 \\
\hline \multirow{2}{*}{ Corporativa } & $\mathbf{N}$ & 9 & 53 & 17 & 11 & 22 & 3 & 3 & 1 & 7 & $(126)$ \\
& $\%$ & 9,4 & 20,5 & 13,4 & 25,6 & 50,0 & 14,3 & 23,1 & 20,0 & 7,7 & 18,0 \\
\hline \multirow{2}{*}{ Individual } & $\mathbf{N}$ & 10 & 75 & 59 & 8 & 10 & 7 & 6 & 0 & 10 & $(185)$ \\
& $\%$ & 10,4 & 29,0 & $\mathbf{4 6 , 5}$ & 18,6 & 22,7 & 33,3 & 46,2 & 0,0 & 11,0 & 26,5 \\
\hline \multirow{2}{*}{$\mathbf{T}$} & & $(96)$ & $(259)$ & $(127)$ & $(43)$ & $(44)$ & $(21)$ & $(13)$ & $(5)$ & $(91)$ & $(699)$ \\
\hline
\end{tabular}

Control Legislativo: 1998-2002 PRD. Control Ejecutivo: 1998-2000 PLD.

Fuente: elaboración propia con datos de OAI-CD/RD.

En 2002-2006 el PRD cuenta con mayoría en la Cámara y hasta 2004 está al frente del Ejecutivo nacional (Hipólito Mejía, PRD). A pesar del escenario propicio para el ejercicio de orientación de la política pública, solo el 18,7\% de las iniciativas de los legisladores perredeístas son de carácter general, siendo además los que favorecen en mayor medida intereses de individuos concretos (68\% de las propuestas). En esta legislatura aumenta la promoción de intereses parroquiales en los distritos en los tres principales partidos. Como muestra la tabla 7, en la bancada del PLD, del $10 \%$ del periodo anterior ascienden al $45 \%$ las iniciativas para gestionar pensiones para electores; en el PRD del $29 \%$ pasan al $68 \%$, y en el PRSC del $46 \%$ al $62 \%$. Los porcentajes más altos en la solicitud de pensiones se ubican en los años con mayoría parlamentaria del PRD (2003 y primer semestre 2006) y en los años en que este partido controlaba también el Gobierno nacional (2003). El aumento de la promoción de intereses individuales podría estar influido por el voto preferencial utilizado por primera vez en estas elecciones de 2002. El pico máximo corresponde al año 2006 (véase gráfico 1), en que se celebraron elecciones legislativas, comenzando después la tendencia decreciente en la asignación selectiva de pensiones, aunque con un ligero repunte en 2010, año también de elecciones legislativas.

Por último, en la legislatura 2006-2010 el PLD cuenta con mayoría en ambas Cámaras y controla también el Ejecutivo (Leonel Fernández, PLD), un escenario propicio en el que los diputados oficialistas someten a trámite parlamentario el mayor 
TABLA 7.

ACTIVIDAD PROPOSITIVA SEGÚN NIVEL DE PARTICULARISMO Y PARTIDO, LEGISLATURA 2002-2006

\begin{tabular}{|c|c|c|c|c|c|c|c|c|c|c|c|c|}
\hline & & PLD & PRD & PRSC & $\begin{array}{l}\text { PLD/ } \\
\text { PRD/ } \\
\text { PRSC }\end{array}$ & $\begin{array}{l}\text { PLD/ } \\
\text { PRD }\end{array}$ & $\begin{array}{l}\text { PRD/ } \\
\text { PRSC }\end{array}$ & $\begin{array}{l}\text { PLD/ } \\
\text { PRSC }\end{array}$ & PPC & FNP & Otras & Total \\
\hline \multirow{2}{*}{ General } & $\mathbf{N}$ & 26 & 51 & 48 & 27 & 7 & 4 & 5 & 6 & 8 & 23 & (205) \\
\hline & $\%$ & 45,6 & 18,7 & 26,1 & 39,7 & 33,3 & 11,1 & 62,5 & 35,3 & 72,7 & 62,2 & 28,8 \\
\hline \multirow{2}{*}{ Corporativa } & $\mathbf{N}$ & 5 & 35 & 22 & 22 & 7 & 16 & 1 & 1 & 0 & 2 & (111) \\
\hline & $\%$ & 8,8 & 12,8 & 12,0 & 32,4 & 33,3 & 44,4 & 12,5 & 5,9 & 0,0 & 5,4 & 15,6 \\
\hline \multirow{2}{*}{ Individual } & $\mathbf{N}$ & 26 & 187 & 114 & 19 & 7 & 16 & 2 & 10 & 3 & 12 & (397) \\
\hline & $\%$ & 45,6 & 68,5 & 62,0 & 27,9 & 33,3 & 44,4 & 25,0 & 58,8 & 27,3 & 32,4 & 55,7 \\
\hline $\mathbf{T}$ & & & $(184)$ & (68) & $(21)$ & (36) & (8) & (17) & $(11)$ & (37) & (713) \\
\hline
\end{tabular}

Control Legislativo: 2002-2006 PRD. Control Ejecutivo: 2000-2004 PRD.

Fuente: elaboración propia con datos de OAI-CD/RD.

número de iniciativas de vocación universal (64\%). Las iniciativas que tienen como finalidad la promoción de intereses generales aumentan en los tres partidos mayoritarios, aunque los representantes del PRSC siguen concentrando el peso de su actividad propositiva en la gestión de pensiones para electores de su circunscripción (55\%). Estos datos apuntan a que el PLD ha sido el partido con mayor vocación normativa en el Congreso en los distintos escenarios de oportunidad, mientras que en los legisladores del PRD y del PRSC ha predominado el rol concesional, determinado no tanto por la oportunidad, sino por una decisión de acción colectiva y tipo de vínculo con el elector.

TABLA 8.

ACTIVIDAD PROPOSITIVA SEGÚN NIVEL DE PARTICULARISMO Y PARTIDO, LEGISLATURA 2006-2010

\begin{tabular}{|c|c|c|c|c|c|c|c|c|c|c|c|c|}
\hline & & PLD & PRD & PRSC & $\begin{array}{l}\text { PLD/ } \\
\text { PRD/ } \\
\text { PRSC }\end{array}$ & $\begin{array}{l}\text { PLD/ } \\
\text { PRD }\end{array}$ & $\begin{array}{l}\text { PRD/ } \\
\text { PRSC }\end{array}$ & $\begin{array}{l}\text { PLD/ } \\
\text { PRSC }\end{array}$ & PPC & FNP & Otras & Total \\
\hline \multirow{2}{*}{ General } & $\mathbf{N}$ & 85 & 52 & 15 & 25 & 20 & 5 & 5 & 2 & 24 & 20 & (253) \\
\hline & $\%$ & 64,4 & 53,6 & 31,9 & 71,4 & 69,0 & 55,6 & 71,4 & 100 & 92,3 & 87,0 & 62,2 \\
\hline \multirow{2}{*}{ Corporativa } & $\mathbf{N}$ & 15 & 16 & 6 & 6 & 7 & 3 & 1 & 0 & 1 & 2 & (57) \\
\hline & $\%$ & 11,4 & 16,5 & 12,8 & 17,1 & 24,1 & 33,3 & 14,3 & 0,0 & 3,8 & 8,7 & 14,0 \\
\hline \multirow{2}{*}{ Individual } & $\mathbf{N}$ & 32 & 29 & 26 & 4 & 2 & 1 & 1 & 0 & 1 & 1 & (97) \\
\hline & $\%$ & 24,2 & 29,9 & 55,3 & 11,4 & 6,9 & 11,1 & 14,3 & 0,0 & 3,8 & 4,3 & 23,8 \\
\hline \multirow{2}{*}{$\mathbf{T}$} & & $(132)$ & $(97)$ & $(47)$ & $(35)$ & $(29)$ & (9) & (7) & (2) & (26) & (23) & (407) \\
\hline & \multicolumn{12}{|c|}{100} \\
\hline
\end{tabular}

Control Legislativo: 2006-2010 PLD. Control Ejecutivo: 2004-2010 PLD.

Fuente: elaboración propia con datos de OAI-CD/RD. 
El punto de inflexión que marca la legislatura 2006-2010 en la promoción generalista de intereses puede ser también reflejo de la interacción estratégica y juegos de veto del partido oficialista en su posición de dominio del Legislativo y del Ejecutivo. Esta legislatura fue la primera en la que el PLD conquistó la mayoría absoluta y primera en la historia democrática del país en la que el PRD no obtiene representación en el Senado. En este contexto favorable, el poder de veto del PLD en el trámite parlamentario aumenta y así lo reflejan los datos, ya que las proposiciones rechazadas en 2006-2010 aumentaron un $52,6 \%$ con respecto a la legislatura anterior ${ }^{11}$. En este poder de veto al inicio de la tramitación legislativa, el partido oficialista podría esconder la intención de limitar el papel de conseguidor que los diputados de la oposición poseen en sus distritos $^{12}$. Por otro lado, el auge de los programas de transferencias que comenzaron en 2004 con las administraciones del PLD, podría haber trasladado el peso del asistencialismo particularista del Legislativo al campo de acción del Ejecutivo. En 2010 los beneficiarios directos de estos programas de la Presidencia identificados con la «Tarjeta Solidaridad» representaban el 9\% de la población y el 14\% del censo electoral, y al igual que las pensiones gestionadas por los legisladores, conllevan asignaciones monetarias mensuales ${ }^{13}$.

\section{«Brokering alone»: individualismo legislativo}

A pesar de la mayor vocación generalista de la actividad propositiva nacional que revelan los datos de 2006-2010, el número de proponentes de las futuras leyes constata, por el contrario, el creciente personalismo en el hemiciclo dominicano y la poca operatividad de las bancadas parlamentarias en la agregación de preferencias. En los doce años que comprende este estudio, más de la mitad de las propuestas que promovían intereses generales fueron elevadas a título individual por un solo diputado $(52,7 \%)$, por lo que no han sido muchas las ocasiones en que el partido ha hablado como una sola voz colectiva, ni habitual el debate entre bancadas para orientar las políticas públicas. En la legislatura 2006-2010, solo el 37\% de las propuestas que promovían

11. Proposiciones rechazadas: 127 en 1998-2002; 590 en 2002-2006, y 1247 en la legislatura 2006-2010. "Trámite de toma de consideración»: cuando la lectura en sesión del enunciado de las iniciativas registradas en el orden del día o su motivación por parte de los proponentes no haya dado motivo a impugnaciones, aplazamiento o peticiones de rechazo. La objeción de un diputado, apoyado por otro, dará lugar a que el Presidente tome el parecer de la Cámara sin necesidad de debate, sobre si se toma o no en consideración el asunto» (art. 74 del Reglamento Cámara de Diputados, 2010).

12. Con la alianza del oficialismo y su principal opositor en 2016, el PLD podría neutralizar estratégicamente la actividad concesional de su socio, ya que el Gobierno Compartido de Unidad Nacional PLD-PRD desdibuja las fronteras Gobierno-oposición, limitando el rédito electoral partidista de este tipo de acciones.

13. Algunos de los más populares son: «Comer es Primero» (20 USD/mes); «Incentivo a la Asistencia Escolar» (5 USD/mes); «Bono Gas» (6 USD/mes) y el «Bono Luz» (9 USD/mes). 
intereses generales fueron elevadas a trámite por dos o más proponentes, mientras que este porcentaje alcanzaba el 54,6\% en la legislatura 1998-2002. La misma tendencia personalista en el trabajo parlamentario se observa en las proposiciones de ley que otorgan beneficios de club y las que perseguían la concesión de una pensión a un elector. Como muestra la tabla 9, ambas fueron tramitadas individualmente en el $61 \%$ y $80 \%$ de los casos en 2006-2010, frente al 44\% y 56\% de la legislatura anterior 1998-2002.

TABLA 9.

ACTIVIDAD PROPOSITIVA SEGÚN NÚMERO DE PROPONENTES (\%), 1998-2010

\begin{tabular}{lccccccccc}
\hline & \multicolumn{3}{c}{ General } & \multicolumn{3}{c}{ Corporativa } & \multicolumn{3}{c}{ Individual } \\
\cline { 2 - 10 } & $\mathbf{9 8 - 0 2}$ & $\mathbf{0 2 - 0 6}$ & $\mathbf{0 6 - 1 0}$ & $\mathbf{9 8 - 0 2}$ & $\mathbf{0 2 - 0 6}$ & $\mathbf{0 6 - 1 0}$ & $\mathbf{9 8 - 0 2}$ & $\mathbf{0 2 - 0 6}$ & $\mathbf{0 6 - 1 0}$ \\
\hline $\begin{array}{l}\text { Un } \\
\text { proponente }\end{array}$ & 42,8 & 55,1 & $\mathbf{6 0 , 3}$ & 44,5 & 47,7 & $\mathbf{6 1 , 4}$ & 56,7 & 72,8 & $\mathbf{8 0 , 4}$ \\
\hline $\begin{array}{l}\text { Dos o más } \\
\text { proponentes }\end{array}$ & 54,6 & 36,0 & 37,7 & 54,6 & 51,3 & 38,6 & 43,2 & 27,3 & 19,5 \\
\hline $\begin{array}{l}\text { Poder } \\
\text { Ejecutivo }\end{array}$ & 2,4 & 8,89 & 1,9 & 0,7 & 0,8 & 0 & 0 & 0 & 0 \\
\hline $\mathbf{T}$ & 100 & 100 & 100 & 100 & 100 & 100 & 100 & 100 & 100 \\
\hline
\end{tabular}

Fuente: elaboración propia con datos de OAI-CD/RD.

El trabajo en solitario de los diputados dominicanos en las tareas de representación podría estar influenciado por el sistema de voto preferencial establecido en 2002 y por la magnitud del distrito. Bajo la modalidad de lista abierta los diputados tratan de diferenciarse del compañero de escaño asignando recursos para su circunscripción o elaborando leyes por las que reclamar crédito. Este deseo tiende a exacerbar el individualismo legislativo y disminuye el valor informativo de las posturas de los partidos (Carey, 2009; Muñoz, 2011). La magnitud promedio de los distritos dominicanos se sitúa en el rango de las circunscripciones pequeñas de 2 a 5 escaños (Nohlen, 2004: 60). Cuanto menor es la magnitud del distrito, mayor es la importancia de los electores en la carrera política de los diputados y menor el control de las cúpulas partidistas en el proceso. Las circunscripciones pequeñas estrechan la relación principal-agente y amplifican el localismo en la representación. Como demostrara Guevara (2004: 96) para el caso de Panamá, en escenarios de competición clientelar, carencia de servicios públicos y sectores marginales, un sistema electoral basado en distritos pequeños tiende a reproducir el particularismo.

La reforma constitucional de 2010 introdujo la figura del «diputado nacional por acumulación» en el Congreso de la República Dominicana, por lo que habría que esperar un menor particularismo en el ejercicio de las labores de representación de estos cinco nuevos legisladores que se unen a los 178 electos en las 32 circunscripciones provinciales. Este tipo de demarcación nacional superpuesta a la de nivel inferior, se establece como mecanismo corrector de la desproporcionalidad y para generar en los 
partidos una visión de política nacional que los desligue de los intereses parroquiales de sus circunscripciones (García Díez, 2001). Aunque la actividad propositiva de estos cinco diputados queda fuera del espectro temporal de esta investigación, un primer análisis exploratorio de los datos apunta a que la circunscripción nacional parece limitar el particularismo en la representación ${ }^{14}$. Así, de las cincuenta iniciativas presentadas por estos diputados en su primer ejercicio, el $94 \%$ de ellas promovían intereses generales.

Sin embargo, el mayor tamaño de la circunscripción no parece fomentar el trabajo de estos representantes en el seno de sus propias bancadas parlamentarias. La tabla 10 revela que -al igual que sus colegas diputados provinciales- los cinco diputados nacionales prefieren trabajar en solitario o con representantes de otras fuerzas políticas antes que con sus compañeros de partido. Por lo tanto, en el caso dominicano la mayor magnitud del distrito de la circunscripción nacional no parece afectar a los niveles de cohesión legislativa. La preferencia por la visibilidad personal del éxito de la gestión individual de la iniciativa (14\%) y la compartida con algunos compañeros (26\%) frente a la actuación conjunta de la bancada $(0 \%)$, podría obedecer a razones estratégicas de carrera política, pero también al tradicional faccionalismo que aqueja a los partidos dominicanos.

TABLA 10.

PROPOSICIONES DIPUTADOS CIRCUNSCRIPCIÓN NACIONAL SEGÚN NÚMERO DE PROPONENTES, 2010

\begin{tabular}{|c|c|c|c|}
\hline Iniciativa Personal & Iniciativa Compartida & Iniciativa Partidista & $\begin{array}{c}\text { Iniciativa } \\
\text { Interpartidista }\end{array}$ \\
\hline Diputado Nacional & $\begin{array}{c}\text { Diputado Nacional } \\
+ \\
\text { otros compañeros de } \\
\text { partido }\end{array}$ & $\begin{array}{c}\text { Diputado Nacional } \\
+ \\
\text { grupo parlamentario }\end{array}$ & $\begin{array}{c}\text { Diputado Nacional } \\
+ \\
\text { diputados de todos } \\
\text { los partidos }\end{array}$ \\
\hline $14 \%(7)$ & $26 \%(13)$ & $0 \%(0)$ & $60 \%(30)$ \\
\hline \multicolumn{4}{|c|}{$(\mathbf{N}=\mathbf{5 0}) 100 \%$} \\
\hline
\end{tabular}

Fuente: elaboración propia con datos de OAI-CD/RD.

Aunque no son muchas las ocasiones en que diputados de partidos diferentes elevan iniciativas conjuntamente (PLD-PRD 6\% en 1998-2002, 2,9\% en 2002-2006 y $7 \%$ en 2006-2010), esta actividad propositiva interpartidaria ofrece información acerca de la cooperación estratégica del presidencialismo pluralista dominicano. Sirva como ejemplo que en las elecciones legislativas de 2006 el PRD y el PRSC concurren en alianza electoral. Sin embargo, sus representantes solo elevaron a trámite cinco iniciativas de naturaleza general de forma conjunta, frente a las veinte ocasiones en que así lo hicieron el oficialista PLD y su opositor PRD (véase tabla 8). En 2002-2006 el PRD y el PRSC -enemigos históricos pero aliados en esta legislatura- colaboraron más para satisfacer los intereses particulares de los electores de sus distritos $(44,4 \%)$ que para proponer leyes generales $(11 \%)$

14. Solo disponibles las iniciativas tramitadas en el periodo agosto 2010-agosto 2014. 
(véase tabla 7). Estos datos revelan que el presidencialismo pluralista dominicano es una modalidad no programática en la que se comparte la gestión clientelar del Estado.

\section{Representación atomizada y movilización clientelar}

El destacado posicionamiento de la República Dominicana en los rankings regionales y mundiales que miden la intensidad de los intercambios de favores por votos, evidencia que los partidos dominicanos se han adaptado al escenario de la democratización conservando el estilo de la política de clientela y manejo patrimonial del Estado. Las tres ideologías caudillistas - el "peñagomismo» socialdemócrata, el «boschismo» estatista reformista y el «balaguerismo» populista- han evolucionado en la etapa de la consolidación hacia la convergencia ideológica y la competencia centrípeta (PELA, 2010). Su función movilizadora no programática gira en torno a su efectividad para distribuir bienes y la alternancia está marcada desde los ochenta por el desempeño macroeconómico. Las propuestas de los diputados para conceder pensiones a electores de su circunscripción al margen del sistema general de beneficiarios son ejemplo del asistencialismo particularista que menoscaba la universalidad de las políticas de protección y previsión. Estas futuras leyes ad hoc "con nombre y apellido" de los beneficiarios lesionan el principio de abstracción y generalidad del ordenamiento jurídico.

Para conocer cuál es el peso de este tipo de iniciativas asistencialistas en la actividad propositiva de los partidos con representación legislativa, se elabora un coeficiente que mide el exceso o defecto de actividad de los legisladores en relación al peso de la bancada de su partido en la Cámara ${ }^{15}$. Como muestran las tablas 11, 12 y 13, los representantes reformistas (PRSC) son los que promueven más intereses clientelares durante todos los años de vigencia del mandato de representación, a pesar de ser la fuerza con menor número de escaños ${ }^{16}$. La sobreactividad particularista de la bancada reformista confirmaría el impacto de la procedencia de las élites en los partidos «internamente movilizados» y su mayor vocación clientelar. En la transición a la política de masas, los actores que ocupaban posiciones en el régimen anterior tenderán a seguir utilizando el patronazgo para la movilización de sus bases con el cambio a la democracia (Shefter, 1994: 29). Estas decisiones de elección social y de organización adoptadas en momentos clave condicionan la orientación de la responsividad a largo plazo. El Partido Reformista (PR) fundado en 1963 por Joaquín Balaguer, hombre fuerte de la dictadura trujillista, se mantuvo en el poder por más de veinte años hasta que el fraude electoral de 1994 precipitara su salida negociada.

15. Se divide el porcentaje anual de proposiciones para conceder una pensión a un particular entre el porcentaje de escaños de esa fuerza política. El valor 1 indica proporción entre iniciativas y peso del partido en la Cámara de Diputados. Valores por debajo de 1 indican déficit de actividad y valores por encima de 1 exceso de actividad.

16. En 1998-2002 el PRSC controlaba el $10 \%$ de los escaños, el $23 \%$ en 2002-2006 y el $21 \%$ en 2016-2010. 
A partir de 2004 el PRD y el PRSC se alternan en la sobreactividad particularista. Los picos máximos en la tramitación parlamentaria de pensiones coinciden con años electorales (legislativas 1998 y 2002; presidencial 2008), lo que revelaría su posible uso como herramienta movilizadora y de recompensa por parte de los partidos de la oposición. La vocación particularista de la agregación de intereses en el sistema de partidos dominicano se observa también en las fuerzas políticas minoritarias. Tal es el caso del Partido Popular Cristiano (PPC) y de la Fuerza Nacional Progresista (FNP), ambos con coeficientes de actividad particularista de 8'42 (2002), 6'23 (2003) y 2’41 (2007) respectivamente. La actual oferta partidista supera la veintena de partidos; sin embargo, este número más que cuantificar el pluralismo democrático, es indicador de las disensiones partidistas y las ambiciones personalistas. La mayoría de los pequeños partidos aliados se han convertido en vehículos para acceder a las redes de patronazgo en las instituciones cedidas en la negociación dejando a un lado su vocación de gobierno ${ }^{17}$ (Benito y Lozano, 2016).

Además de la actividad propiamente normativa en el Congreso, los legisladores dominicanos ejercen de gestores de bienes públicos en sus distritos a través del Fondo de Gestión Social Legislativa. Esta asignación presupuestaria es conocida como «barrilito» (senadores) y "cofrecito» (diputados), aunque el primero de los apelativos es el que ha acaparado la designación popular. Mientras que los senadores reciben entre 9000 y 20500 dólares mensuales dependiendo de la población de sus provincias, los diputados reciben entre 1200 y 2500 . Si bien el sobrenombre de «barrilito» deriva del anglicismo pork barrel, no es una manifestación de este tipo de política en la que los legisladores estadounidenses compiten por atraer recursos para sus distritos, ya que en la versión dominicana es una asignación fija determinada por el número de habitantes de la provincia y la autonomía presupuestaria del Congreso dominicano. Hasta 2008 no existía control alguno sobre esta actividad que los legisladores realizaban a través de sus propias fundaciones. Desde entonces, estas donaciones han pasado a ser financiadas mensualmente con recursos públicos sin otro filtro institucional que el mero registro contable en el Congreso. Las asignaciones del «barrilito» se sitúan en la dinámica de la relación patróncliente de las tradicionales relaciones de patronazgo, en las que el cliente utiliza el canal particularizado de atención entre ambos para someter a la subjetividad del diputado la concesión del favor. Medicinas, alimentos, becas, materiales de construcción, sufragar las fiestas patronales o los uniformes deportivos de los clubes infantiles locales entre otros, son los destinos de estas regalías otorgadas por los legisladores de las que emanará el compromiso moral del elector de estar en deuda con el representante que le ayudó ${ }^{18}$.

17. Tras las elecciones de 2010, los aliados oficialistas obtuvieron el control de la Lotería Nacional (BIS), del INESPRE (PCR), del Instituto de Bienes Nacionales (PQDC) y de Exteriores (PRSC).

18. En uso de su posición mayoritaria en las instituciones y en lo que podría ser una nueva estrategia del PLD para neutralizar la labor concesional de la oposición, en octubre de 2014 la Presidencia de la Cámara retiró el "barrilito" de la gestión individual de los legisladores y se atribuyó su gestión directa. Con esta medida, el partido oficialista de turno pasará a ser el patrón único de la asistencia social legislativa a través de la figura de su presidente en la Cámara de Diputados. 


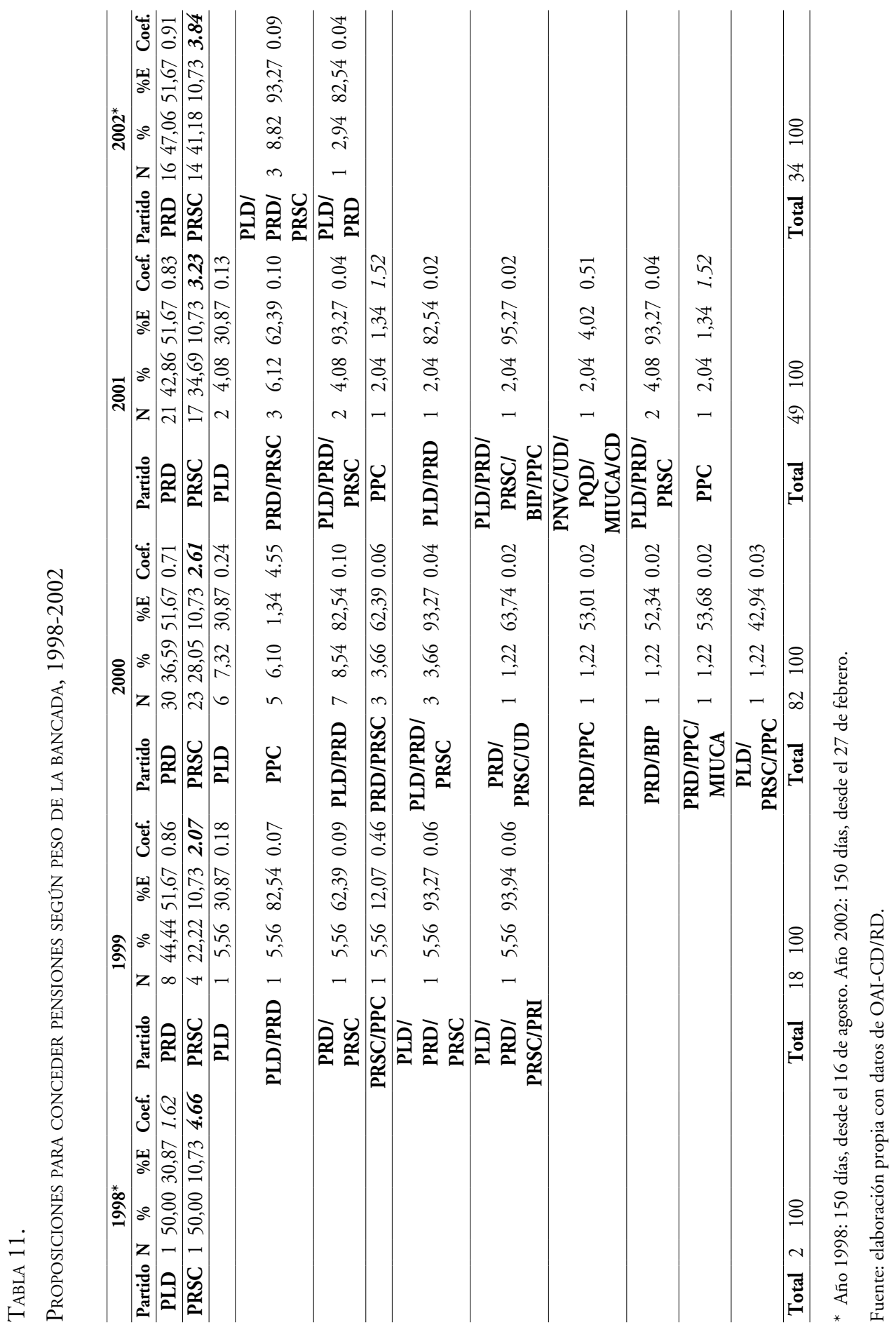




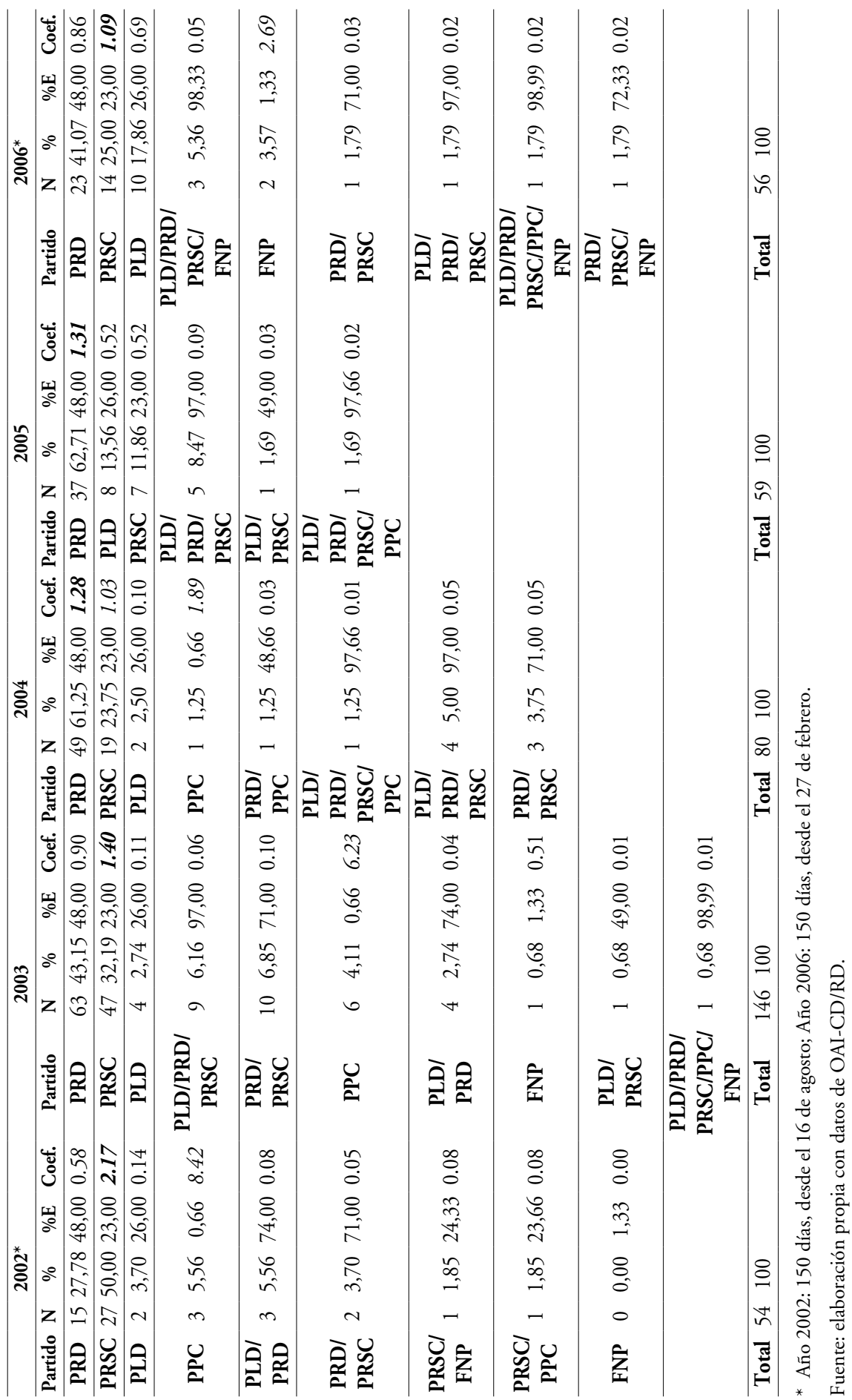




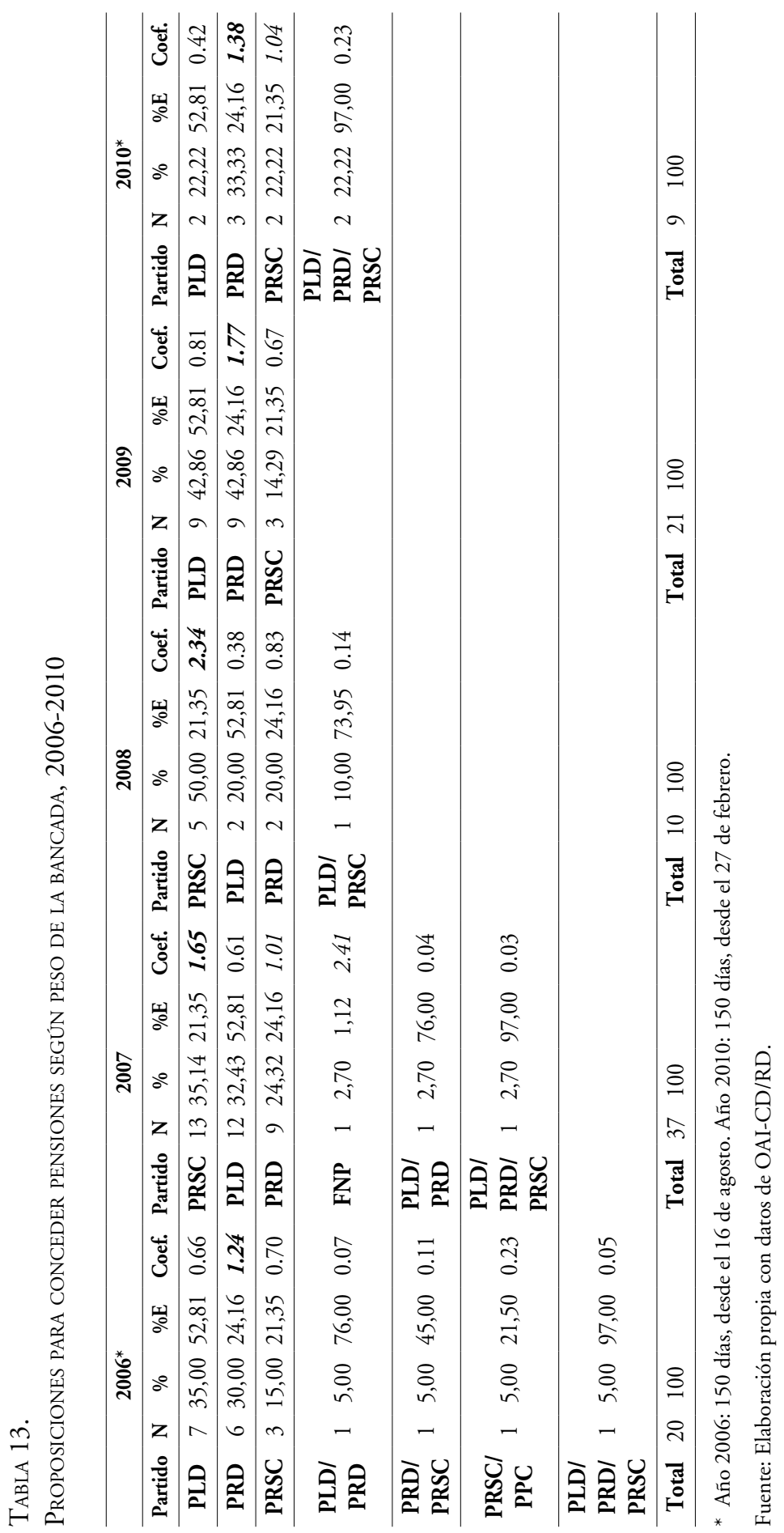




\section{CONCLUSIONES}

Este trabajo propone una clasificación del grado de inclusividad de las proposiciones de ley para identificar la mayor o menor vocación particularista de la función normativa. El indicador sugerido permite acercarse a la labor de representación más cercana en tiempo al acto de delegación entre principal-agente $\mathrm{y}$, por tanto, menos afectada por los filtros institucionales, que tienden a desvirtuar el mandato (agenda setting, conquista de apoyos, vetos entre facciones de una misma bancada...). Los datos muestran que el mandato de representación en la República Dominicana tiene un marcado focus distrital y está guiado por la defensa de intereses localistas. La vinculación de las élites al territorio convierte al diputado dominicano en un bróker resolutivo en el distrito más que en un agente propositivo en el Congreso Nacional.

El estudio revela el predominio de la interacción de los «empresarios políticos» y «servidores del distrito» (Siavelis y Morgenstern, 2008), en la que el diputado ejerce de conseguidor de derechos selectivos y favores personales. La función normativa se singulariza menoscabando la abstracción que garantiza la previsibilidad y seguridad jurídica en un Estado de derecho. La promoción de intereses parroquiales y la escasa fiscalización apuntarían a una distribución de tareas que confirmaría en el país el «secreto de la ineficiencia» (Amorim y Santos, 2003) en la relación Legislativo-Ejecutivo y la marginalidad del Legislativo dominicano en la formulación de políticas relevantes de alcance nacional. En este escenario, la representación se atomiza en un mar de particularismos que no pone en peligro la fluidez institucional ni el liderazgo nacional. La promoción legislativa de intereses empresariales por la vía de exenciones contraviene el criterio de generalidad en la distribución de las cargas públicas en materia fiscal impositiva, mientras que el papel de gestores de pensiones y mecenas que otorgan regalías a través del «barrilito» desvirtúa sus funciones de representación acercándolas a unas más propias de la Administración. La legislación individualista y su labor asistencial en los distritos profundizan la desmaterialización de la política social (Adelantado y Scherer, 2008), reconduciéndola a un acto de altruismo paternalista no sujeto a control de legalidad o justicia social, pero fundamental en la carrera política de los legisladores para mantener a sus clientelas. La politización de su distribución lesiona la universalización de los resultados democráticos del mandato de representación.

Tal como ha identificado la literatura en otros escenarios, el papel de conseguidor y el ejercicio en solitario de las funciones de representación de los legisladores dominicanos podrían estar influenciados por la naturaleza del financiamiento de los partidos, la propia clase política y el sistema electoral. Sin embargo, el efecto de la magnitud del distrito no parece estar tan claro en el país, ya que si bien la actividad propositiva de los cinco diputados nacionales revela una menor vocación concesional, esta no se realiza en el seno de la bancada. La responsividad particular es la opción estratégica elegida por los actores dominicanos en el marco de un sistema de partidos no programáticos y vinculación racional directa entre políticos y electores en el país. Los datos 
confirman que el escenario de oportunidad que genera el juego de minorías y mayorías del partido oficialista de turno no es tan determinante como la decisión de elección social adoptada por cada partido. En este sentido, el PRSC es el que más proposiciones de ley particularistas somete a trámite parlamentario, independientemente de su fuerza como partido opositor en la Cámara, mientras que el PRD lo hace con fines movilizadores en escenarios propicios pero altamente competitivos -en 2004, año de elecciones presidenciales y en las que pierde el control del Ejecutivo- y en escenarios electorales más adversos como el de 2010, cuando pierde el control del Legislativo. El PLD es el que muestra una mayor vocación generalista, ya que cuando este partido controla el Ejecutivo disminuye el número de proposiciones de ley de naturaleza individual.

El cambio de actitud parroquial hacia otra más orientada a consideraciones de índole nacional observado en la legislatura 2010-2016 podría estar determinado por los juegos de veto que resultan del peso de las mayorías y los intereses de las elites políticas. Como advirtieran Cox y Morgenstern (2001) en su estudio sobre México, Brasil y Argentina, este punto de inflexión en un legislativo marginal y fines distributivos (Lowi, 1964) como el dominicano, podría deberse al cambio de escenario de una «mayoría parroquial venal», a otro de "mayoría subordinada» en la actual coyuntura de dominio de las instituciones del oficialista PLD con doce años consecutivos en el poder. Teniendo en cuenta la tesis de Bertino (2013) sobre los sistemas bicamerales incongruentes, cabría esperar un comportamiento más particularista en los senadores dominicanos elegidos por mayoría simple en distritos uninominales que en los diputados aquí estudiados electos bajo reglas proporcionales. A pesar de ello, no es posible afirmar el carácter reactivo del Poder Legislativo en la República Dominicana ya que este trabajo no considera la tasa de aprobación de las 1863 proposiciones de ley elevadas a trámite en el periodo estudiado.

El descenso de la actividad clientelar distributiva de las proposiciones de ley en la Cámara de Diputados con fines asistencialistas en las legislaturas de mayoría del PLD no parece ir de la mano de una mayor actividad de vocación redistributiva cuando este partido ocupa el Ejecutivo. La política social de las últimas administraciones del oficialista PLD se ha caracterizado por la relevancia decreciente de la provisión universal redistributiva frente al auge protagónico de la asistencia de focalización individual. La baja incidencia absoluta de los programas de transferencias monetarias -con las tasas de filtración y sub cobertura más altas de América Latina (BID, 2016: 50)- cuestiona el carácter inclusivo de la política social en la República Dominicana.

A pesar del menor peso del parlamento en los regímenes presidenciales, este trabajo demuestra que el Legislativo es un agente con voluntad tanto para la distribución estratégica (asignación selectiva) como para la redistribución (universalización). El predominio de una u otra dependerá de los incentivos que se generen en la dinámica partidista, institucional y en la relación con el Ejecutivo. La tipología presentada a partir del caso dominicano de presidencialismo dominante (Zovatto y Orozco, 2008: 51), abre nuevas líneas de investigación que ponderen el papel del Legislativo en otras democracias de competencia clientelar bajo diseños presidencialistas puros 
como México; con matices parlamentarios como Paraguay, o parlamentarizados como Argentina y Colombia ${ }^{19}$.

\section{Referencias}

Acemoglu, Daron y James Robinson. 2006. The economic origins of democracy and dictatorship. Cambridge: Cambridge University Press.

Adelantado, José y Elenise Scherer. 2008. «Desigualdad, democracia y políticas sociales focalizadas en América Latina», Revista Chilena de Administración Pública, 11: 117-134.

Amorim, Octavio y Fabiano Santos. 2003. «The Inefficient Secret Revisited: Legislative Input/Output of Brazilian Deputies», Legislative Studies Quarterly, 28: 449479. Disponible en: https://doi.org/10.3162/036298003X200962.

Andeweg, Rudy y Jacques Thomassen. 2005. "Modes of political representation: toward a new typology", Legislative Studies Quarterly, 30 (4): 507-528. Disponible en: https://doi.org/10.3162/036298005X201653.

Ansolabehere, Stephen y James Snyder. 2003. «Party control of state government and the distribution of public expenditures», Scandinavian Journal of Economics, 108 (4): 547-569. Disponible en: https://doi.org/10.1111/j.1467-9442.2006.00470.x.

Banco Interamericano de Desarrollo (BID). 2016. ¿Cómo se redistribuyen los recursos públicos en República Dominicana?». Santiago de Chile: División de protección social y salud.

Barreda, Mikel y Leticia Rodríguez. 2015. «Los diputados en sus distritos y en el Congreso: ¿representación desde arriba o desde abajo?», Revista Latinoamericana de Politica Comparada, 9: 11-33.

Benito, Ana B. y Rotsay Rosales. 2011. «Marco normativo del sistema de partidos en República Dominicana: las reglas del juego interpartidario e intrapartidario», en PFGP (ed.), Diagnóstico sobre la situación del sistema de partidos en República Dominicana 2005-2010. Santo Domingo: USAID, IIDH-CAPEL.

Benito, Ana B. 2015a. Clientelismo en democracia: factores explicativos de la politica particularista en la República Dominicana [tesis doctoral]. Universidad de Salamanca, Salamanca.

Benito, Ana B. y Wilfredo Lozano. 2016. «Viejos patrones y nuevos actores. Evolución del sistema de partidos en la República Dominicana», en F. Freidenberg (ed.), Los sistemas de partidos en América 1978-2015 (pp. 397-443). Ciudad de México: UNAM.

Bertino, María P. 2012. «La producción legislativa como variable dependiente. Agenda de investigación en América Latina», en Cuarto Congreso Uruguayo de Ciencia Política. Montevideo: Asociación Uruguaya de Ciencia Política.

19. En 2010 República Dominicana, Argentina, México, Paraguay y Panamá lideraban en este orden la «Escala de Clientelismo en América Latina» elaborada por LAPOP. 
Bertino, María P. 2013. «Legisladores o representantes? Evidencia sobre la producción legislativa en bicameralismos de las provincias argentinas». Instituto de Iberoamérica, Documentos de Trabajo, 7. Salamanca: Instituto de Iberoamérica.

Bogliaccini, Juan A. y Juan P. Luna. 2016. "Deflecting my burden, hindering redistribution. How elites influence tax legislation in Latin America», en The Political economy of Social Protection Systems. UNU-WIDER, Working Paper, 92.

Boucoyannis, Deborah. 2015. «No Taxation of Elites, No Representation. State Capacity and the Origins of Representation", Politics and Society, 43 (3): 303-332. Disponible en: https://doi.org/10.1177/0032329215584765.

Carey, John M. 2009. "Ingeniería electoral. ¿Qué nos muestran las investigaciones sobre los efectos anticipados de las reformas electorales?, en A. Fontaine et al. (eds.), Reforma del sistema electoral chileno. Santiago de Chile: PNUD.

Chasquetti, Daniel. 2008. Democracia, presidencialismo y partidos politicos en América Latina: evaluando la difícil combinación. Montevideo: Ediciones Cauce.

Cox, Gary, Scott Morgenstern y Leandro Wolfson. 2001. «Legislaturas reactivas y presidentes proactivos en América Latina», Desarrollo Económico, 163 (41): 373393. Disponible en: https://doi.org/10.2307/3456006.

Centro Regional de Estrategias Económicas Sostenibles (CREES). 2013. Estadísticas. Disponible en: http://www.crees.org.do/es/.

De la Calle, Luis. 2005. "Carreteras y votos: el PSOE y las políticas territoriales de construcción de coaliciones de apoyo, 1982-1996». Revista de Investigacines Politicas y Sociológicas, 4 (1): 65-96.

De la Cruz, Serafino. 2011. "Continúa la fragmentación del país». Observatorio Político Dominicano. Santo Domingo: Funglode. Disponible en: http://www.opd.org.do.

Eisenstadt, Shmuel y Rene Lemarchand. 1981. Political clientelism, patronage and development. Beverly Hills: Sage.

Ellis, Andrew, Jesús Orozco y Daniel Zovatto. 2009. Cómo hacer que funcione el sistema presidencial. Making Presidentialism Work. Ciudad de México: IDEA, UNAM.

Fairfeld, Tasha. 2010. «Business Power and Tax Reform. Taxing Income and Profits in Chile and Argentina", Latin American Politics and Society, 52 (2): 37-71. Disponible en: https://doi.org/10.1111/j.1548-2456.2010.00081.x.

García Montero, Mercedes. 2008. Instituciones y actividad legislativa en América Latina. Documentos CIDOB, 23. Barcelona: CIDOB.

García Montero, Mercedes. 2009. Presidentes y Parlamentos. ¿Quién controla la actividad legislativa en América Latina? Madrid: CIS.

García Díez, Fátima. 2001. «Reformas electorales y sistemas de partidos parlamentarios en América Central». América Latina Hoy, 27: 37-65.

Gilens, Martin. 2012. Afuence and Influence. Economic Inequality and Political Power in America. Princeton: Princeton University Press.

Guevara, Carlos. 2004. "Calidad de la representación política y tamaño de las circunscripciones electorales: una comparación de las asambleas panameñas de 1945 y 1999», Revista de Ciencia Politica, 24 (2): 94-115. 
Guzmán, Abel. 2017. «Financiamiento de la campaña coloca al PLD y a su cúpula en situación difícil», Periódico Diario Libre, 3-6-2017. Disponible en: https://www. diariolibre.com/noticias/politica/financiamento-de-la-campana-coloca-al-pld-y-a-sucupula-en-situacion-dificil-CX7246602.

Hagopian, Frances. 2005. «Derechos, representación y la creciente calidad de la democracia en Brasil y Chile», Política y Gobierno, 12 (1): 41-90.

Instituto Dominicano de Seguros Sociales (IDSS). 2015. Estadísticas. Disponible en: http://www.idss.org.do/.

Indridason, Indridi H. 2007. «Duration of Coalition Bargaining: The Impact of Particularistic Politics», en Annual Meeting of the Midwest Political Science Association. London: MPSA.

Kitschelt, Herbert y Daniel M. Kselman. 2011. «Organizational Extensiveness and Political Clientelism», en Workshop on Democratic Accountability Strategies. Durham: Duke University.

Kitschelt, Herbert y Steven Wilkinson. 2012. «Vínculos entre ciudadanos y políticos: una introducción». Instituto de Iberoamérica, Documentos de Trabajo, 11. Salamanca: Instituto de Iberoamérica.

Krehbiel, Keith. 2004. «Legislative organization», Journal of Economic Perspectives, 18 (1): 113-128. Disponible en: https://doi.org/10.1257/089533004773563467.

Kuznets, Simon.1955. «Economic growth and income inequality. American Economic Review, 45: 1-28.

LAPOP. 2010. The Americas Barometer by the Latin American Public Opinion Project.

Landé, Carl. 1977. "The dyadic basis of clientelism», en S. Schmidt et al. (eds.), Friends, followers and factions: A reader in political clientelism. Los Ángeles: University California Press.

Lanzaro, Jorge. 2003. Tipos de presidencialismo y coaliciones politicas en América Latina. Buenos Aires: CLACSO.

Lowi, Theodore J. 1964. «American business, public policy, case studies, and political theory», World Politics, 16 (4): 677-715. Disponible en: https://doi. org/10.2307/2009452.

Mainwaring, Scott y Shugart Mathew. 2002. Presidencialismo y democracia en América Latina. Barcelona: Paidós.

Mejía, Andrés, Aníbal Pérez-Liñán y Sebastián Saiegh. 2009. «Las bases partidarias de la legislación particularista en Ecuador y Paraguay», en F. Freidenberg y M. Alcántara (eds.), Selección de candidatos, politica partidista y rendimiento democrático. Ciudad de México: TEDF.

Meltzer, Allan y Scott Richard. 1981. "A rational theory of the size of government», Journal of Political Economy, 89 (5): 914-927. Disponible en: https://doi. org/10.1086/261013.

Muñoz, Juan M. 2011. «Sistema electoral y personalismo de los diputados hondureños». Boletín Datos de Opinión Elites Parlamentarias Latinoamericanas, 30. 
Nitcher, Simeon. 2008. «Vote buying or tornout buying? Machine politics and the secret ballot», American Political Science Review, 102 (1): 19-31. Disponible en: https://doi.org/10.1017/S0003055408080106.

Nohlen, Dieter. 2004. Sistemas electorales y partidos politicos. Ciudad de México: FCE. PELA (2010). Proyecto Élites Parlamentarias, Manuel Alcántara (dir.). Universidad de Salamanca.

Piattoni, Simona. 2001. Clientelism, Interests, and Democratic Representation: The European Experience in Historical and Comparative Perspective. Cambridge: Cambridge University Press. Disponible en: https://doi.org/10.1017/CBO9781139175340.

Pitkin, Hanna F. 1967. El concepto de representación politica. Madrid: CEPC.

Quinn, Dennis P. y Robert Y. Shapiro.1991. «Business Political Power. The Case of Taxation», American Political Science Review, 85 (3): 851-874. Disponible en: https://doi.org/10.2307/1963853.

Ramírez, Adriana. 2010. «El sistema de partidos multinivel en estados unitarios: la competencia electoral en República Dominicana (1978-2010)», Working Paper, Universidad de Salamanca.

Rosas, Guillermo y Kirk Hawkins. 2008. «Turncoats, true believers, and turnout: Machine politics in the absence of vote monitoring», Washington University in St. Louis and Brigham Young University [inédito].

Seddon, Jessica, Alejandro Gaviria, Ugo Panizza y Ernesto Stein. 2002. «Political Particularism around the World». BID Working Paper, 463. Banco Interamericano de Desarrollo.

Shefter, Martin. 1994. Political parties and the State. The American Historical Experience. Princeton: Princeton University Press.

Shepsle, Kenneth y Marc Bonchek. 1997. Analyzing politics. Rationality, Behavior and Institutions. Nueva York: W. W. Norton.

Siavelis, Peter y Scott Morgenstern. 2009. «Reclutamiento y selección de candidatos en América Latina: un marco para el análisis», en F. Freidenberg y M. Alcántara (eds.), Selección de candidatos, politica partidista y rendimiento democrático. Ciudad de México: TEDF.

Stokes, Susan. 2005. «Perverse Accountability. A Formal Model of Machine Politics with Evidence from Argentina», American Political Science Review, 99 (3): 315325. Disponible en: https://doi.org/10.1017/S0003055405051683.

Suárez, Nelson. 2013. Primer Informe de monitoreo aplicación de la Ley de Función Pública No. 41 de 2008 y su Reglamento. Santo Domingo: PC.

Taylor Michelle y Chris Díaz. 1999. "Who Gets Legislation Passed in a Marginal Legislature and is the Label Marginal Legislature Still Appropriate? A Study of the Honduran Congress", Comparative Political Studies, 32 (5): 589-625. Disponible en: https://doi.org/10.1177/0010414099032005003.

Zelaznik, Javier. 2012. "Agenda presidencial y apoyo legislativo», en A. Mustapic, A. Bovencchi y J. Zelanik (coords.), Los legisladores en el Congreso argentino: prácticas y estrategias. Buenos Aires: Instituto Torcuato Di Tella. 
Zovatto, Daniel y Jesús Orozco. 2008. Reforma politica y electoral en América Latina 1978-2007. Ciudad de México: UNAM-IDEA.

Presentado para evaluación: 7 de febrero de 2017.

Aceptado para publicación: 29 de mayo de 2017.

ANA B. BENITO

ana.benito@cepc.es

Doctora en Ciencia Política por la Universidad de Salamanca. Investigadora postdoctoral del Programa García Pelayo en el Centro de Estudios Políticos y Constitucionales (CEPC) de España. Línea de investigación: determinantes institucionales y partidistas del particularismo y la corrupción legislativa en América Latina. 